Journal of Critical Race Inquiry

Volume 7, Number 1 (2020) pp. 23-45

\title{
New Medical Studies, Same Old Politics: The Effects of Anti-Black Racism on Penetrative Trauma Research
}

\author{
Jina Fast \\ Women and Gender Studies, West Chester University
}

\begin{abstract}
The effects of medical racism on the health outcomes of Black people in the U.S. are well recorded in prominent medical journals and governmental study data. Despite this documentation, there has yet to be broad structural change addressing the multiple oppressive systems intersecting to create adverse outcomes for Black people. Consequently, trust in medicine and medical practitioners continues to be low, which impacts the relationship between Black people and dominant institutions of medicine, including medical research. In this paper, I analyze the ethics of a forthcoming study on penetrative wound treatment from Temple University Hospital in Philadelphia. Using Franz Fanon's analysis of medicine as a form of colonial practice and Dorothy Roberts' analysis of the biological reduction of social inequities to problems of Black people themselves, I argue that the Philadelphia Immediate Transport in Penetrating Trauma Trial, or PIPT study 1) fails to meet the ethical requirement of treating study participants as human beings; 2) fails to engage with deep, structural inequities that produce higher rates of gun violence in communities from which study participants will be drawn; and 3) functions to reinforce stereotypes of Black men as violent and as thus to blame for the violence they face individually and at a community level. Without addressing the intersectional, structural, and interpersonal forms of oppression framing studies like the PIPT, I contend that medical researchers, medical practitioners, and policy makers cannot fully appreciate the extent to which race and anti-Black racism function to prevent the health and well-being of Black people.
\end{abstract}

Keywords: Medical ethics, critical race theory, anti-Black racism, penetrative trauma 


\section{Introduction}

When white, upper- and middle-class, cis-hetero people think about medicine, they are likely to imagine it as a healing field, as a means of mitigating or remedying pain. Yet for many, medical institutions have functioned as primary sources of suffering, alienation, and social control. In the U.S. and globally, the oral and written traditions of Black people, LGBTQ (Lesbian, Gay, Bisexual, Transgender, and Queer) teens and adults, and nondominant language speakers have conveyed distrust of the medical establishment, which is predominantly run by and geared to benefit white people (Jaiswal \& Halkitis, 2019; Sheppard, Huei-Yu Wang, Hurtado-deMendoza, Sutton, \& LaVeist, 2019). In the academy, many social scientists specializing in critical race and postcolonial theory have explored clinical knowledge and medical power as explicit sources for practicing and maintaining colonial violence and anti-Black racist oppression (Adas, 1989; Fanon, 1959; Fausto-Sterling, 1996; Hoberman, 2012; Keller, 2014; Roberts, 1998).

In what follows, I consider the effects of anti-Black racism on a forthcoming study from Temple University's School of Medicine, entitled the "Philadelphia Immediate Transport in Penetrating Trauma Trial," or PIPT study. My central purposes here are threefold. First, I seek to show that the PIPT study continues an anti-Black racist and classist legacy in U.S. medical practice and theory through failing to account for intersectional, structural, and interpersonal forms of oppressions. Second, I apply Dorothy Roberts' critical analysis of the problematic understandings of race deployed in medicine by academics and medical doctors to the ethical failings of the PIPT study. Finally, I offer an interpretation of the backlash the study has faced by people of colour in Philadelphia using Franz Fanon's analysis of the effects of colonialism on the relationships between colonized groups and dominant medical institutions. Through the above analysis, coupled with examination of public commentary as well as a personal interview with the lead researcher of the PIPT study, my intention is to reveal the complexity of the ethical issue(s) entailed and to show that, in studying oppressed groups, multiple levels of structural and interpersonal relationships must be considered by those who carry out such studies.

Importantly, I do not dispute the understanding of human physiology or the empirical evidence grounding the PIPT study; rather I argue biomedical ethicists, medical researchers, as well as the local and federal boards and agencies that approve, fund, and permit studies must also attend to the socio-historical context(s) of the PIPT study to proceed ethically. Thus, the first section of this paper argues the necessity of placing the PIPT study within a U.S. socio-historical context of the medical and social abuse of Black patients. The second and third 
sections consider some of the effects of failing to do so on both the communities researched and on how researchers pose problems and solutions for racialized groups. Some of the concerns I raise throughout the paper are the waiver of informed consent procured for the study, the socio-historical context of the resistance of Black Philadelphians to the PIPT study, the social conditions that make it more likely that Black men from low-income backgrounds will function as the primary medical subjects in the study, and finally, the effects this study could have both in reinforcing racist discourse and further alienating Black people from a white-dominant medical establishment. Without consideration of these structural components framing the study, medical researchers, medical practitioners, and policy makers cannot fully appreciate the extent to which race and anti-Black racism function to prevent the health and well-being of Black and brown peoples.

Instead, my concerns here derive from personal and professional interests that inevitably intersect in my analysis of the PIPT study. First, as a Philadelphia resident, I am technically included as a possible study participant unless I opt out through a process explained in a subsequent section. However, as a white, cisgender woman residing in a majority Black, middle-class neighborhood in Center City that experiences relatively low rates of violent crimes, my personal likelihood of being part of the study is statistically quite low. Thus, I do not have the same experiential relationship to the study as Black and brown Philadelphians, and do not intend here to speak for them. Indeed, it would be remiss for me to suggest that I, as a white person, have the same affective connection as Black and brown persons do to histories of abuse and exclusion from dominant medical institutions. In fact, my ability to produce this essay is connected to my whiteness - if we consider my access to education, and to the (white) researchers who lead the PIPT study. That said, I am a feminist epistemologist and critical race theorist. My approach to research is to explicitly interrogate the standpoints all groups involved occupy and the power — formal and informal — they have at their disposal to advance their own interests and construct meaning and value. My goal is, therefore, to use my areas of expertise (and privilege) to analyze a specific study and to serve as an ally to Black and brown people in Philadelphia affected by medical racism. In short, I seek here to amplify Black and brown Philadelphians' voices by theorizing the how and why of the role of race, racialization, and racism in science and medicine. 


\section{Contextualizing the PIPT Study in a History of U.S. Medical Racism}

U.S. medical history is fraught with examples of the abuse of Black enslaved persons as non-consenting medical subjects for experimentation and the collective trauma that endures (Broussard, 2013; Jacobs, 1861; Washington, 2009). Post-emancipation, the picture does not much improve. The revelation of the injustices of the Tuskegee Syphilis Study in 1972, 40 years after the study began and 20 years after penicillin was recognized as the standard of care for syphilitic patients, stands as a trenchant example of the failure of medical ethics to constrain the practices of researchers and doctors in relation to poor, Black patients. The Tuskegee Study is routinely recognized as problematic today; however, why it is viewed as unethical has less to do with how the study was conceived and more to do with the failure to provide penicillin as treatment. While it is important to consider practically what led to the unnecessary suffering of hundreds of Black men in this study, it is necessary also to consider the impact scientific, social, and political discourses on race played in framing the background for the study itself.

In the case of the Tuskegee Study, racist ideas masquerading as science, coupled with the social and political reinforcement of ideas of "innate difference" between racialized peoples played central roles in framing the study as legitimate for white researchers and white-dominant agencies (Brandt, 1978; Jones, 1981; Washington, 2006). Furthermore, informed consent by study participants was deemed unnecessary because they were never considered to be patients (Jones, 1981). The failure in Tuskegee, in examining the background of the study, is not that the eventual remedy was never administered, but that study subjects were never viewed as human beings to be cured. Rather, the purpose of the study was to use poor, Black men as objects of scientific inquiry to provide knowledge and thus power to white researchers, individually, and white institutions collectively (Brandt, 1978; Jones, 1981).

Turning to the PIPT study, the most convincing evidence for its legitimacy derives from a retrospective cohort study of trauma-registered data in Philadelphia studied by Band et al. (2014). As the largest study to date examining the relationship between out-of-hospital mode of transport and mortality in penetrating trauma-where penetrating trauma is defined as an injury that occurs when an object pierces the skin and enters the body - it suggests the need for change in standard procedure in the treatment of penetrative wound patients during transport to hospital. Band et al. (2014) found increased adjusted survival among three key subgroups of penetrative trauma patients transported by police, who notably have no department-sponsored formal medical training and carry no department-issued medical equipment. In subgroup analysis, patients with severe injury (Injury Severity Score $>15)$ (OR 
0.73; 95\% CI 0.59 to 0.90 ), patients with gunshot wounds (OR 0.70; 95\% CI 0.53 to 0.94), and patients with stab wounds (OR $0.19 ; 95 \%$ CI 0.08 to 0.45$)$ were more likely to survive if they received basic care, as opposed to advanced medical care, in transport.

Yet, despite suggestive data and the experiential knowledge of trauma surgeons, basic care has not been introduced as best practice due to barriers in producing level one data in large randomized control studies (Band et al., 2014; Kragh et al., 2011; Stiell et al., 2008; Yoganandan \& Pintar, 1997). The proposed PIPT study seeks to use standards in medical research to produce level one data and establish guidelines for protocol in immediate transport following penetrative trauma. To test the Temple University researchers' hypothesis, patients included in the study will be randomized based on the dispatch number city paramedics receive. Odd numbers will receive advanced care, which includes inserting a breathing tube and supplying intravenous fluids when necessary. Even numbers will receive what is known as basic care, which can include hemorrhage control, breathing assistance with a bag-valve mask, dressing wounds, and aligning bones (Temple University, n.d.). All will be immediately transported to the closest level one trauma hospital regardless of type of care.

My reservations with the PIPT study are neither based on my review of the retroactive cohort study data, nor with the physiological grounding of the hypothesis. This appears to be quite sound, and the study could produce evidence for change in standard practice that does help future patients who encounter such trauma. Instead, the problems with the proposed study, I argue, are ethical and connect to a socio-political history of medical abuse of Black and brown low-income patients. And herein lies the basis of my concern and the concerns voiced by Black and brown Philadelphians themselves: that Black and brown people will, again, be reduced to the status of body-objects for the advancement of practitioners and medical care for the abstract/non-racialized subject. For example, the PIPT study could advance the research agendas of the Temple University medical researchers who lead the study, thus enabling career advancement of white individuals through the use of study subjects whose lives are generally considered less valuable. Take for example the following: when asked by a Vice News correspondent what will happen if the hypothesis of the study is wrong, Temple University Hospital surgeon-in-chief and lead researcher on the study Dr. Amy Goldberg stated "Well then we will have learned something, and we will change our practices" (2016). While on the one hand this is merely part of the process of scientific inquiry, on the other it is a dehumanizing framing which, when heard by marginalized populations, can appear to cast aside the importance of their lives for the good of scientific practice and theory. To understand why the latter interpretation might appear, I will 
contextualize the PIPT study within a history of medical abuse, like the failures of the Tuskegee Study.

The similarities between the PIPT study and historical anti-Black racist medical practice and theory have not been lost on Philadelphia's Black and brown communities, as many explicitly refer to Tuskegee in raising their objections. For example, in an email to lead researcher Dr. Zoe Maher, one Philadelphia resident referred to the PIPT study as "Tuskegee Part II" (Z. Maher, personal communication, June 7, 2017). Similar concerns have been voiced by Philadelphians of colour in interviews with national news organizations, like Vice News (2016) and NPR (Moselle, 2016), and local publications, such as The Temple News (Brennan, 2016). In an interview with NPR (Moselle, 2016), community activist and Philadelphia resident Charles Lanier voiced concern over the fact that some people will need to be "sacrificed" for there to be a new prescription of care. Lanier was also interviewed by Vice News and repeats this concern, adding that "researchers don't know if they could be enacting more harm than good" (2016). Yolanza Gonzalez, also a community member and city council aid, expressed similar trepidation, stating, "It almost seems like we will be gambling with peoples' lives" (Moselle, 2016). Another issue raised by community members is that many haven't heard about the study, but are going to be possible subjects nonetheless. When asked about the study by Kelly Brennan of The Temple News, one North Philadelphia resident replied, "I haven't heard of it" (2016). This is echoed in a Vice News interview from the same year where several residents of Hunting Park, a neighborhood in Philadelphia with higher than average rates of gun violence and penetrative wound deaths, noted 1) they personally haven't heard about the study, 2) didn't think that others had, and 3) didn't know how to opt out of it if they disagreed with it (2016). At the very least, these reactions seem to indicate that the required community outreach was ineffective.

As a university professor, I also cover the PIPT study in my upper-level Gender, Race, and Science course and the students of colour (some of them Philadelphia residents themselves) do not hesitate to express both misgivings and outright disgust about its existence. For example, one female student of colour noted that she was "unsurprised" by the existence of the PIPT study and connected our considerations in class to the fact that her father doesn't trust doctors, preferring instead to treat illness with homeopathic remedies and tinctures. Another male student of colour, after learning about the circumstances for exemption to the study, asked rhetorically: "How is it legal to run studies on people without their consent?" His point connects to a claim made by North Philadelphia resident Jason Wood who is quoted by Brennan of The Temple News as stating, "The power should be in the hands of the people. It should be their right to decide [what treatment they get]" (2016). 
These justifiable concerns are further confirmed through an analysis of the history of U.S. medical abuse of Black and brown people via sanctioned studies like the aforenamed Tuskegee Study. For one, the pool of study subjects is comparable: the Tuskegee Study and the PIPT study rely on predominantly low-income Black men as subjects, thus the lives that will be "gambled with" are not white lives, but those of people of colour. Second, the ethical standard of informed consent by participants in medical trials required by the FDA and HHS has been waived. Typically, study participants must understand the study parameters, procedures, risks, and be able to provide consent. With the PIPT, one does not consent to participate. Rather, all Philadelphians who are over the age of 18, not pregnant, and not incarcerated are automatically enrolled as potential subjects (Temple University, n.d.). To be excluded, one must explicitly opt out online and wear a wristband for at least the next five years. The burden is thus placed on the individual and does not take into account challenges individuals might face in learning how to opt out, accessing internet, or being able to wear a wristband long-term.

Before any trial receives such waiver, the FDA requires a review by an independent physician and the hospital's institutional review board (IRB) - a committee comprised of experts and laypeople. To be approved, the board would have to agree on several points: 1) that the trial addresses a life-threatening situation, 2) that the experimental treatment is at least as good as established conventional therapy, and 3) that the condition of patients is likely to be such that it would be very difficult to obtain consent in advance from patients themselves or their legal representatives. The IRB that reviewed the PIPT study proposal agreed the study meets all the above requirements (Temple University, n.d.). First, the board agreed that penetrative trauma by gunshot or stabbing is often life-threatening. Second, transport to hospital and care during said transport is necessary, and basic care has been shown to produce better outcomes than advance care when retroactive data, military data, and non-human animal data are considered. Finally, the board agreed that loss of consciousness or compromised consciousness is common in penetrative trauma, thus a waiver from informed consent is justifiable.

As added protection to human subjects in studies where an exemption of consent is granted by the IRB, the FDA also requires advanced public notice, consultation with representatives of the community, an independent board to monitor the studies as they progress, and publication of all results (FDA, 2013). However, what constitutes a "completed community consultation," as seen in the case of the PIPT study, is open to interpretation by the individual board themselves. That is, the FDA and HHS do not set a standard for the type or the amount of community consultation required, leaving said determinations up to the IRB 
to assess in the context of local issues (FDA, 2013). Additionally, sites, sponsors, and IRBs are merely encouraged, but not required, to consider the effectiveness of their community consultation (FDA, 2013). Giving researchers the opportunity to locally assess the distinctive needs of the population from which study subjects will be drawn can be read as a positive turn away from the abstract to the particular (Lock, 1987, 1993). However, one should be wary of the power discrepancies possibly reinforced as well as the implicit benefit of the doubt given to researchers to protect their patients. Doctors and medical researchers are not immune to, and have actively contributed to, medical folklore about Black peoples and blackness, which have perpetuated stigmatization of Black people as inherently inferior (Fausto-Sterling, 1996; Kaplan \& Rogers, 1994; Lewontin, Rose, \& Kamin, 1984). Furthermore, a history of medical racism has left emotional wounds in Black and brown communities, so it is important to consider whether outreach is effective, lest more damage occur.

In the next section, I further draw out the ethical problems of the PIPT study, contextualizing it within a contemporary U.S. landscape of prevailing health care disparities and the dominant accounts that erase the roles racialization and anti-Black racism play. In contrast to these arguments that, by their own accounts, accept that disparities exist but do not explore the social category of race as a mitigating factor, Dorothy Roberts (2012) provides an analysis that centres race as a socio-political framework. Positioning race as a socio-political category of meaning enables a more robust evaluation of the power relations at work within dominant institutions of medicine broadly conceived, and for my purposes here shows the impact of race on the PIPT study formation and subsequent institutional approval.

\section{On the Necessity of Theorizing about Race as a Social Category in Medicine}

The passage of the Affordable Care Act in the U.S. in 2010 increased access to health care for people in all racial categories (Gaffney \& McCormick, 2017). Yet, discrepancies in quality of care and health care outcomes persist between white and Black patients as reported in the National Health Care Disparities Report (NHDR) in all subsequent years (2011-2016), suggesting that access to health care alone cannot transform the poor health care outcomes of Black people in an anti-Black racist society. Instead of focusing merely on access to health care, the social roots of discrepancies must be examined including, but not limited to, doctorpatient relationships and what makes Black people sicker in the first place. Within my analysis, examining the social roots of health discrepancies is important for it shows that Black people are expected to submit to medical care as PIPT study subjects without 1) white 
doctors' attitudes toward Black patients being addressed, and 2) adequate attention paid to the marked inequities in health and health care outcomes between Black and white patients.

Instead of addressing the aforementioned, medical practitioners and institutions have reacted to evidence of anti-Black racism in interpersonal and institutional relationships in medicine with ambivalence (Hoberman, 2012). Medical journals routinely publish reports confirming race-based health disparities, name these disparities as intolerable and call, albeit abstractly, for action to reverse them (Hoberman, 2012). Despite this lip service, I argue that scientists, doctors, and medical journalists utilize rhetorical strategies that allow them to deplore racialized disparities while simultaneously distancing themselves from responsibility. Furthermore, the sterile conceptual language of racial "disparities" and "cultural differences," - dubbed bureaucratic language by Hoberman (2012) in Black and Blue: The Origins and Consequences of Medical Racism - can be understood as white-concealing language, in that it functions to obscure biased behaviours buried in statistics and anonymity (Hardeman, Medina, \& Kozhimannil, 2016; Sharma \& Kupar, 2016).

Some physicians have reacted more strongly, casting aside responsibility of doctors and medical institutions in producing good or bad patient outcomes. Instead they locate blame for disparities in the failures of Black peoples to be compliant, in so-called biological differences, and in geographic inequality. Many theorists and politicians have been quick to side with these physicians, arguing that race and racism play little to no role in health disparities (Epstein, 2005). Dorothy Roberts (2012), however, challenges these claims that racial disparities in health result from race-based genetic differences or race-neutral economic differences. Roberts disagrees with the claims of Sally Satel and Jonathon Klick (2006), for example, who argue that geography, rather than race, plays a greater role in explaining differences in health and health care. As their reasoning goes, data clearly shows people residing in areas with a greater concentration of Black peoples have statistically poorer health than people living in areas with higher concentrations of whites. Thus, Satel and Klick (2006) argue, the problem is the places where Black people live, rather than racist practitioners, institutions, and politics that delineate resources for medical care (Acevedo-Garcia, Lochner, Osypuk, \& Subramanian, 2003; Hoberman, 2012; Roberts, 2012).

But, as Roberts shows, this argument doesn't perform the work suggested. Rather, she argues, geographical — and the coinciding economic — disparities are evidence of racism enacted through government policies and private business practices which have led to inferior and inadequate resources in communities where Black people reside (Bell, 1992; Roberts, 2012). Furthermore, the geographic approach to understanding health disparities fails because it doesn't theorize the role between race and socioeconomic status. To be Black in an anti- 
Black racist society is to experience significant barriers to health and well-being that are social and directly impact one's geographic and economic prospects, including job discrimination, housing discrimination, chronic exposure to stress, segregation in unhealthy neighbourhoods, transmission of harms from one generation to the next through the fetal environment, and so on, that imprint upon physiology (Acevedo-Garcia et al., 2003; LaVeist, Pollack, Thorpe, Fesahazion, \& Gaskin, 2011). Using the term inequities reinforces the fact that these discrepancies are not random, but rather produced through decisions about resource allocation. Within my analysis of the PIPT study, this is significant for it suggests that solving any medical problem, for example survival in the event of encountering a penetrative wound, requires analysis of and attention to social frameworks of equity and resource allocation.

A second common approach to addressing racial discrepancies in health is to collapse the social body and the biological body. Unlike the first approach, the second explicitly names race as a factor in health and health care outcomes by reducing the social category of race to biological difference (Roberts, 2012; Sharma \& Kupar, 2016). On this reading, race-based discrepancies in incidence and outcome result from genetic vulnerabilities in Black people, thus reinforcing the idea of the natural inferiority of Black peoples themselves (Williams, 2017). There are, however, two fundamental problems with this approach. The first concerns the methods employed. In the research surveyed by Roberts, genotypes of subjects were never studied and genetic link was argued as explanatory only in the absence of a positive causal link to other proposed factors (Roberts, 2012). Second, there is ample data suggesting that race, as a genetic category, is a falsehood (Cooper, et. al., 2005; Sharma \& Kupar, 2016; LaVeist et al., 2011).

The question is not whether genes affect health, because of course they do, but rather whether genetic difference can explain racial discrepancies in health. By contrast, the harms of using race as a biological marker have been well covered by critical race theorists, postcolonial theorists, and feminist epistemologists of science (Adas, 1989; Fausto-Sterling, 1996; Kaplan \& Rogers, 1994; Krieger \& Basset, 1986; Said, 1978). Yet, using race as a marker of inherent disposition is still common, and while the signifiers may have shifted from length of humerus and protrusion of the mandible to more sophisticated tools - including genetics and epigenetics - the consequences remain similar (Duster, 2005). Disparities in the health outcomes of heart disease, cancer, asthma, and obesity are central to Roberts in her study (2012), but the failure to care and attend to the heart disease that Black people face shares a similar anti-Black racist foundation that the PIPT study lives amid. For instance, if those who have power in terms of directing policy and care utilize racist stereotyping to frame patients who are obese or suffer from heart disease as "doing it to themselves" then fewer 
social resources are allocated to them (Williams, 2017). This lack of care is arguably intensified when perceived violence becomes part of the circumstances for injury and need for medical care.

In short, Roberts' analysis points us to two considerations the PIPT study researchers must attend to in performing their study. First, they must consider how the study itself attempts to operate from a perspective of race neutrality. This is evident even in the language used to describe the intention(s) of the PIPT study: The goal is to "save peoples" lives"; "We can't wait because as we wait people are dying"; and "We don't want to hurt anyone"; "For this patient population less is more" (Moselle, 2016; Temple University, n.d.; Vice News, 2016, emphasis added). The fact that the majority of those enrolled in the study and affected by penetrative wound death in Philadelphia are people of colour goes unmentioned. Furthermore, in failing to attend to social discrepancies that increase the likelihood of experiencing penetrative wounds, the researchers reinforce the idea that race does not play a role in compromising the medical options of Black people (Hoberman, 2012). In attempting to avoid the racial politics of said study, the researchers risk exacerbating distrust between white researchers and Black research subjects. This has already appeared in post-outreach survey data, suggesting that Philadelphia residents generally believe this study is important, but worry about using low-income Black men whose consent is waived as test subjects (Moselle, 2016).

Second, the PIPT study researchers ought to consider how this study could possibly reinforce racist stereotypes about Black people, and specifically Black men. For while there may be the desire to frame blatantly racist ideas about the innate dispositions of Black peoples as remnants of the past, these ideas are still advanced today (Bell, 1992; Kaplan \& Rogers, 1994; Sharma \& Kupar, 2016; Williams, 2017). The PIPT, as it focuses on penetrative wounds experienced primarily by Black men, could generate heightened visibility of violence encountered by Black men. In a just world, this could incite a positive reaction wherein the public, policy makers, educators, and medical practitioners come together to consider the social roots of violence experienced by Black men (Christensen, Gill, \& Perez, 2016; hooks, 2004). However, in an anti-Black racist world, the PIPT study will likely reinforce the stereotype that Black men are predisposed to violence and violent acts.

Thus, while it is important to address the medical needs of Black people in the U.S. as medical needs, they are not merely biological or physiological, but rather appear within social contexts. That is, attending to penetrative trauma patients requires simultaneously being concerned with the root causes of penetrative trauma in the United States. Regarding the PIPT study, I maintain this should include developing collaborative partnerships that focus on 
eliminating the roots violence by considering the impacts of poverty, the prison industrial complex, the war on drugs, racist discrimination in housing and employment, and health care inequities which contribute to the overall lived experiences - and challenges - of Black peoples (Feagin \& Bennefield, 2014).

In the final section, I use Franz Fanon's analysis of the effects of colonialism on medical practice to understand the criticisms Philadelphia's Black and brown communities have made of the PIPT study. Fanon's work, I believe, enables a deeper consideration of the manifestation of alienation in postcolonial institutional relationships - in this case between Black and brown people in Philadelphia and a major university hospital. What should be additionally troubling, though perhaps not surprising to critical race theorists, is the extent to which the lead researchers of the study are unable (or arguably unwilling) to conceive of the problems in affective and socio-historical terms. Rather, the researchers appear to see noted concerns as an inability of Black and brown communities to understand the physiological evidence grounding the hypothesis, or as a deficiency in communication between researchers and the community. This must be addressed, I contend, through a deeper understanding of the ways in which colonial, postcolonial, and neocolonial subjects view predominantly white medical institutions' and researchers' intentions.

\section{Understanding the Distrust of Medical Institutions by Colonized Groups}

As a Philadelphia resident and teacher-scholar at a local institution, I contacted the lead researcher of the PIPT study, Dr. Zoe Maher, through my university email and requested an interview. The first email sent went unanswered, but my second received an invitation to interview her in her office at Temple University Hospital. In the exchange leading up to interview, which was recorded with her consent, I disclosed the areas of my research and my intention for the interview - namely that it would serve as background information and her understanding of the reactions to the study would help inform a section of this current paper.

In the interview, Dr. Maher argued that explaining the physiology of trauma should make those listening more comfortable with the idea of waived informed consent because the study is based in sound theory and backed by empirical data (Z. Maher, personal communication, June 6, 2017). In brief, she stated "one can see it just makes sense" (Z. Maher, personal communication, June 6, 2017). To some degree, her statement is accurate. Objectively, all other things being equal, studying penetrative trauma field care in the proposed manner should produce positive outcomes for future patients suffering penetrative 
wounds. However, as indicated by the reactions of Philadelphians of colour, the study being "rational" and based in empirical evidence is not sufficient to mitigate concerns. Maher recognized this, as she decided to push back the official start date of the study to perform more community outreach. This decision, by the measures of my analysis, is a good one. But, while I commend Maher for her attention to the well-being of Black and brown Philadelphians, I argue that community outreach is inadequate to address the concerns raised.

To discern why more community outreach is necessary but not sufficient, I turn to the failure of the PIPT study team to conceive of the problem itself. Toward the conclusion of the interview Maher pulled up a short yet pointed email she sent to her research team. In the email, she asked her team members simply, "How can we build trust between low-income, Black Philadelphians and white doctors?" (Z. Maher, personal communication, June 6, 2017). As the PIPT study invokes exception from consent, it is essential for trust to exist between potential patients and doctors in the Philadelphia community. This question, however, appears only after resistance from the Black community. Like the Tuskegee Study, the absence of this question prior to the pushback reveals a lack of consideration for the humanity or perspectives of Black people (Bell, 1992; Du Bois, 1903; Gordon, 2000). For if the effects on Black test subjects are detrimental, I argue, then the blame is placed on incomplete data, the differences in circumstances between situations encountered by military personnel and Black civilians, "racial and physiological differences" between Black and white peoples, and so on (FaustoSterling, 1996; Roberts, 1998, 2012).

Fanon's analysis of colonial medicine in A Dying Colonialism (1959) aids in clarifying the persistent distrust of a white-dominant institution of medicine by people of colour. Fanon, notably, is studying a French-occupied Algerian population, while Black people in the U.S. have lived amid circumstances of colonial practices of an occupying state to which they are supposed to belong. Nevertheless I contend that the application of Fanon's work is appropriate as the psychological and material effects are comparable. To begin my analysis, I draw connections through applying Fanon's revolutionary method.

In his first major work, White Skin, Black Masks (1952/2008), Fanon argues the study of the Black person requires ontogenic, phylogenic, and sociogenic approaches. Like in biology, ontogenic studies address the individual organism in question, while phylogenic studies address the species. The central distinction here is between the individual and the structure, yet, Fanon argues that such a distinction tends to miss a third equally, if not more important factor - the sociogenic. The sociogenic takes seriously that which emerges from the social world, which includes the intersubjective relationships of culture, language, history, education, medical practice, and economics. 
For Black people, then, a sociogenic analysis reveals the dehumanizing relationship between the individual and the structural in an anti-Black world. Generally speaking white people, as individuals, are served by institutions, and through being served by institutions their humanity is reinforced as meaningful and important to the State (Bell, 1992; Fanon, 1952/2008, 1959; Gordon, 1999; Henry, 2000). By contrast, Black people are dehumanized by being marked in what Fanon scholar Lewis Gordon names as "perverse anonymity" (1999). When a Black person reaches out within an anti-Black society, they do not find reciprocity but rather discover themselves in situations of epistemic closure. The white world, by simultaneously overdetermining and erasing the Black person, presumes complete knowledge of the phenomenon - the Black person in situation as "problem" — and thus does not have to put effort toward further knowledge discovery (Bell, 1992; Dubois, 1903; Gordon, 1995, 1999, 2015).

The result of this is an anonymity that is different from the namelessness that characterizes most generalized components of the social world, which are defined by the indefinite article "a"(Gordon, 2015). There are general characteristics mapped onto "a graduate student" or "a teacher" or "a waiter" and we admit limited knowledge of these persons as individuals occupying these roles (Sartre, 1943). Yet, as Gordon explains, within an anti-Black world "[t]he encounters become skewed as we presume complete knowledge by virtue of individuals who may occupy these roles or social identities" (2015, p. 49). The gulf between identity and being is collapsed as Black people are rendered as perversely anonymous, and a new ontological reality manifests for the person whom is transformed as Gordon puts it "an overdetermined declaration" rather than an open query $(2015$, p. 49). One result of this new ontological reality important here is the dehumanizing treatment experienced within institutional relationships. For if questions no longer must be asked regarding the Black person because they are fully known, then this person does not have to be spoken to, asked to consent, asked what they desire, how they can be helped, and so on (Gordon, 1999, 2015).

To take a sociogenic approach to considering studies like the PIPT study, I can compare the anti-Black social world of occupied Algeria and the anti-Black postcolonial or neocolonial world of the United States. For one, the effects are similar. Like the reaction of Black Philadelphians to the PIPT study, the Algerians responded to European medical care and doctors (Black and white) with skepticism and resistance. As Fanon explains, going to the doctor is never a simple affair for the occupied Algerian subject, but an ordeal, imbued with the totality of the colonial order (1959). Similarly, in the U.S., subjects who experience penetrative wounds may be escorted to the Emergency Department by police transport, but 
they do not necessarily trust that the (white colonial) system is there to serve them. Instead, Black low-income Philadelphians fear they will be stereotyped as drug-addicted, violent, noncompliant, and irresponsible if they confess the problems they experience. Moreover, they may legitimately fear that their wounds will further enact blame and assumed guilt upon Black people (Hoberman, 2012). Thus, to allow for the study of their bodies following penetrative trauma can be read as admittance to the stereotypes, rather than understanding violence as emanating from complex and oppressive social orders.

This failure of trust can become epistemic (Fricker, 2003). Trust, for Black people in an anti-Black world, is rendered impossible because, on the one hand, the social value of the words of Black peoples is negated while, on the other hand, white dominant societies use their bodies to solve a medical problem - in the case of the PIPT study, penetrative trauma. But the complex social inequities contributing to risk of penetrative trauma cannot be systemically addressed under white supremacy because, in order to preserve normative whiteness and protect "good" white people, the trauma Black people experience is framed as a problem of Black individuals and Black humanity (Gordon, 2000).

Importantly then, Philadelphians of colour attending outreach sessions are responding not merely to the rational description of the physiology of trauma, as Maher imagines they should be. Rather, they are interpreting the study within a social milieu constituted by power discrepancies, anti-Black racist prejudices, structural violence against Black people, and racialized resource inequities. These social (dis)orders place Black people in a position wherein trusting white people and white institutions becomes irrational and a risk of life (Fanon, 1952/2008, 1959; Gordon, 1995, 2015; Harris, 1993). The mitigation of pain is not a service Black people have been routinely offered through dominant institutions (Brandt, 1978; Fausto-Sterling, 1996); thus in the event they are offered such assistance, they have reason to be suspicious. Historically, care has not been proffered benevolently, but rather for the good of the colonizer (Fausto-Sterling, 1996; Harris, 1993; Jones, 1981). At the very least, the colonized, in accepting the colonizer's services, are required (or more often forced) to give up autonomy and control, in effect admitting they are incapable of self-governance (Baderoon, 2013).

Thus, trapped in a series of double binds, Black patients lose a part of themselves any way they choose (Fanon, 1959). To admit the PIPT study should proceed without the formal consent of low-income Black people renders one a traitor to themselves and their people; yet, if they don't accept the parameters of the study, they might be more likely to die in an encounter with a penetrative wound. It is to consent to the idea that maybe racist ideologies about the innateness of Black people's violence is correct - that Black people need to be fixed, 
rather than people experiencing social problems in need of addressing (Bell, 1992; Gordon, 2000). It also, I argue, risks erasing the history of the use of medical racism as an arm of control over Black people, a history that white people and doctors in the present do not have to know in order to be considered knowledgeable, competent, good (Hoberman, 2012).

Maher's statement then, that the study "just makes sense," is at best naïve and at worst seeks to actively circumvent this history. Additionally, Maher's claim overlooks and obscures the negative feelings of Black and brown Philadelphians within a postcolonial world where access to good medical care and doctors who care is not guaranteed (Anderson, 1998; Krieger \& Basset, 1986; Roberts, 1998; Washington, 2006). Therefore, to transform the trust of Black Philadelphians in the face of the upcoming PIPT study, I argue, the underlying social disorder must be acknowledged and treated.

While Maher eventually asks this important question regarding trust, many physicians write off Black patients" concerns and distrust as "backwardness" or "attempts to hold on to original culture" (Fanon, 1959; Henry, 2000). Fanon writes, "In a non-colonial society, the attitude of a sick man in the presence of a medical practitioner is one of confidence. The patient trusts the doctor; he puts himself in his hands. He yields his body to him" (1959, p. 123). Colonial domination and anti-Black racism, by contrast, give rise to whole complexes of defensive behaviours and refusals as an effort to keep away from the psychological and physical violence of the colonial world (Gordon, 2015; hooks, 2004; Henry, 2000; Roberts, 1999; West, 1991).

In the U.S., the deplorable health conditions of slavery and the medical experimentation such as that which occurred during the Tuskegee Syphilis Study have left an imprint on the relationships between doctors and Black patients (Braunstein, Sherber, Schulman, Ding, \& Powe, 2008; Bronson \& Nuriddin, 2014; George, Duran, \& Norris, 2014). The effects of mistrust are detrimental in that mistrust has been linked to poorer health, health care outcomes, and well-being for Black peoples (Hall, Dogan, Zheng, \& Mishra, 2001; Jacobs et al., 2006; Shavers, Lynch, \& Burmeister, 2002). One such area in which research reveals the consequences of Black patients' mistrust is in the attitudes and choices of Black patients experiencing end-stage renal disease. For those suffering from end-stage renal disease the best option for most patients is to receive a kidney transplant from a living donor (LDT). Yet, what contributes to patients' decisions regarding whether to opt for a kidney transplant or continue with dialysis is not whether a kidney is available or the empirical data on best practices. Rather, researchers have shown that decreased levels in trust in health care, physicians, and hospitals coupled with high levels of racial inequity in care significantly contribute to negative attitudes toward LDT (McDonald, Powell, Perryman, Thompson, \& 
Jacob-Arriola, 2013). In the U.S., the consequence has been that Black people are less likely to receive organ transplants and less likely to become donors themselves, both of which perpetuate disparities in health outcomes (McDonald et al., 2013). The reactions of Black Philadelphians to the forthcoming PIPT study, I contend, represent analogous fears and mistrust. Black communities in Philadelphia, collectively, fear putting themselves and their loved ones in the hands of doctors who may not view them as human beings.

Importantly, in practice, building trust between the dominant group and the colonized must focus not on changing the perceptions of the marginalized, but on the current behaviours and attitudes of doctors, which will in turn affect the beliefs of the marginalized group (Hall et al., 2001; Murray, 2015). Trust is a process that must be cultivated through the revealing of humanity and support in past experiences. The past mistreatment of Black patients cannot be erased, but it can be acknowledged and addressed, creating space for the work required to improve the relationship between Black peoples and white institutions and institutional practitioners in the present-which will in turn become part of the past for future reference (George, Duran, \& Norris, 2014). Community outreach designed to fulfill the needs of one study is not going to solve complex and multi-layered structural problems of U.S. medical racism and social inequities. Maher's decision to postpone the start date of the study and engage in more community outreach is a good start but, unless there is greater attention to the role social inequities play in medical distrust, Maher's attempt at reparative work will be futile.

\section{Conclusion}

In concluding, it is instructive to consider public policies that have successfully brought structural changes to race and class differentials in health care. Contemporary research in Canada and many European countries has shown that well-run nationalized health care can have positive systemic effects (Feagin \& Bennefield, 2014). Countries with nationalized systems where race and class are not primary determinants in access to health care and type of care usually have less health care inequality than the U.S. because there is less inequity in division of said social resource (Acevedo-Garcia et al., 2003; Olafsdottir, 2007; Wilson, 2009). Even in the U.S., the introduction of progressive policies in the past has functioned to close the white-Black mortality gap to some degree. For example, during the 1960s-1980s anti-poverty programs were introduced and significantly reduced racial and class segregation in health care institutions and differentials in health care outcomes (Krieger et al., 
2008; Roberts, 2012). However, subsequent cuts to government programs designed to benefit people of colour and low-income people in the U.S. retracted these gains (Feagin \& Bennefield, 2014). Thus, while access to health care certainly plays a role in improved health outcomes, I suggest that what also must change is the ways in which marginalized groups feel about medical institutions and care (Fricker, 2003; Hall et al., 2001; Murray, 2015). Access may seem mundane, but coupled with shifts in other institutions and ideological frameworks can initiate a broad re-envisioning of the relationship between a historically oppressive institution and the people who have been oppressed.

Fanon's observations, Robert's analysis of race, and a socio-historical perspective regarding the relationship between people of colour and white medical institutions are all pertinent in considering the resistance of Black and brown Philadelphians to the PIPT study. To accept medical institutions and practitioners who have historically proffered abuse, Black and brown peoples' experiences must be acknowledged and the repercussions of this abuse must be more comprehensively addressed. One strategy is the active development of trust. Yet, trust can only occur when a marginalized population is able to participate in institutions that serve them and when social inequities do not reductively determine their relationship(s) to said institutions. Maher, in her work, is attempting to simultaneously offer medical aid, grasp complex social relationships, and build trust between Black Philadelphians and medical institutions. However, without systemic changes addressing structural inequities and the perverse anonymity Black people face in Philadelphia and throughout the U.S., Maher's individual efforts will be limited and studies like the PIPT study will be nearly impossible to conduct ethically.

\section{References}

Adas, M. (1989). Machines as the measure of men: Science, technology, and ideologies of western dominance. Ithaca, NY: Cornell University Press.

Anderson, W. (1998). Where is the postcolonial history of medicine? Bulletin of the History of Medicine, 72(3), 522-30.

Acevedo-Garcia, D., Lochner, K. A., Osypuk, T. L., \& Subramanian, S. V. (2003). Future directions in residential segregation and health research: A multilevel approach. American Journal of Public Health, 93(2), 215-221. 
Baderoon, G. (2013). States of public being: Public selves and national privacies. Journal for Islamic Studies, 33, 77-100.

Band, R., Salhi, R., D. Holena, Powell, E., Branas, C., \& Carr, B. (2014). Severity-adjusted mortality in trauma patients transported by police. Annals of Emergency Medicine, 63, 608-614.

Bell, D. (1992). Faces at the bottom of the well: The permanence of racism. New York, NY: Basic.

Brandt. A. (1978). Race and research: The case of the Tuskegee Syphilis Study. The Hastings Center Report, 8(6), 21-29.

Braunstein, J., Sherber, N., Schulman, S., Ding, E., \& Powe, N. (2008). Race, medical researcher distrust, perceived harm, and willingness to participate in cardiovascular prevention trials. Medicine, 87(1), 1-9.

Brennan, K. (2016, November 8). TUH delays victim study until everyone is better informed. The Temple News.

Bronson, J., \& Nuriddin, T. (2014). "I don't believe in doctors much": The social control of health care, mistrust, and folk remedies in the African American slave narrative. Journal of Alternative Perspectives in the Social Sciences, 5(4), 706-732.

Broussard, P. A. (2013). Black women's post-slavery silence syndrome: A twenty-first century remnant of slavery, Jim Crow, and systemic racism - Who will tell her stories? The Journal of Gender, Race, and Justice, 16(2), 373-421.

Christensen, C., Gill, E., \& Perez, A. (2016). "The Ray Rice domestic violence case: Constructing Black masculinity through newspaper reports. Journal of Sport \& Social Issues, 40(5), 363-386.

Cooper, R., Wolf-Maeir, K. Luke, A., Adeyemo, A., Baegas, J., Forrester, T., Thamm, M. (2005). An international comparative study of blood pressure in populations of European vs. African descent. BMC Medicine, 3, 1-8.

Dubois, W.E.B. (1903). The souls of black folk: Essays and sketches. Chicago, IL: A.C. McClurg \& Co.

Duster, T. (2005). "Race and reification in science." Science, 307(5712), 1050-81.

Epstein, R.A. (2005). Disparities and discrimination in health care coverage: A critique of the Institute of Medicine Study. Perspectives in Biology and Medicine, 48(1), 26-41.

Fanon, F. (1959). A dying colonialism. New York, NY: Grove Press.

Fanon, F. (1961). The wretched of the earth. New York, NY: Grove Press.

Fanon, F. (2008). Black skin, white masks. New York, NY: Grove Press. (Original work published 1952). 
Fausto-Sterling, A. (1996). Gender, race, and nation: The comparative anatomy of "Hottentot" women in Europe. In J. Terry, \& J. Urla (Eds.), Deviant Bodies (pp. 19-48). Indianapolis: Indiana University Press.

FDA. (2013). Guidance for Institutional Review Boards, clinical investigators, and sponsors: Exception from informed consent requirements for emergency research. Retrieved from https://www.fda.gov/media/80554/download

Feagin, J., \& Bennefield, Z. (2014). Systemic racism and U.S. health care. Social Science and Medicine, 103, 7-14.

Fricker, M. (2003). Epistemic injustice and a role for virtue in the politics of knowing. Metaphilosophy, 34(1/2), 154-173.

Gaffney A., \& McCormick D. (2017). The Affordable Care Act: Implications for health care equity. Lancet, 389, 1442-1452.

George, S., Duran, N., \& Norris, K. (2014). A systematic review of barriers and facilitators to minority research participation among African Americans, Latinos, Asian Americans, and Pacific Islanders. American Journal of Public Health, 104(2), e16-e31.

Gordon, L. (1999). Bad faith and antiblack racism. Atlantic Highlands, NJ: Humanities Press.

Gordon, L. (2000). Dubois' humanistic philosophy of the human sciences." The Annals of the American Academy of Political and Social Science, 568, 265-280.

Gordon, L. (2015). What Fanon said: A philosophical introduction to his life and thought. New York, NY: Fordham University Press.

Hall, M., Dogan, E., Zheng, B., \& Mishra, A. (2001). Trust in physicians and medical institutions: What is it, can it be measured, and does it matter? Milbank Quarterly, 79(4), 613-639.

Hardeman, R. R., Medina, E. M., \& Kozhimannil, K. B. (2016). Structural racism and supporting Black Lives - The roles of health Professionals. New England Journal of Medicine, 375(22), 2113-2115.

Harris, C. (1993). Whiteness as property. Harvard Law Review, 106(8), 1707-1791.

Henry, P. (2000). Caliban's reason. New York, NY: Routledge.

hooks, b. (2004). We real cool: Black men and masculinity. New York, NY: Routledge.

Hoberman, J. (2012). Black and blue: The origins and consequences of medical racism. Berkley, CA: UC Press.

Jacobs, E., Rolle, I., Ferrans, C., Whitaker, E., \& Warnecke, R. (2006). Understanding African Americans' views of the trustworthiness of physicians. Journal of General Internal Medicine, 21(6), 642-647. 
Jacobs, H. (1861). Incidents in the life of a slave girl written by herself. Boston, Massachusetts: Thayer and Eldridge.

Jaiswal, J., \& Halkitis, P. (2019). Towards a more inclusive and dynamic understanding of medical mistrust informed by science. Behavioral Medicine, 45(2), 79-85.

Jones, J. (1981). Bad blood. New York, NY: The Free Press.

Kaplan, G., \& Rogers, L. (1994). Race and gender fallacies: The paucity of biological determinist explanations of difference. In E. Tobach, \& B. Rossoff (Eds.), Challenging racism and sexism: Alternatives to genetic explanations of difference. New York, NY: The Feminist Press at CUNY.

Keller, R. (2014). Colonial madness: French psychiatry in North Africa. Chicago: University of Chicago Press.

Klick, J., \& Satel, S. (2006). The health disparities myth: Diagnosing the treatment gap. Washington, DC: American Enterprise Institute Press.

Kragh J., Littrel M., Jones J., Walters, T., Baer, D., Wade, C., Holcomb, J. (2011). Battle casualty survival with emergency tourniquet use to stop limb bleeding. Journal of Emergency Medicine, 41(6), 590-597.

Krieger, N., \& M. Basset. (1986). The health of Black folk. Monthly Review, 28(3), 161-169.

Krieger, N., Rehkopf, D. H., Chen, J. T., Waterman, P. D., Marcelli, E., \& Kennedy, M. (2008). The fall and rise of US inequities in premature mortality: 1960-2002. PLoS Medicine, 5(2), 227-41.

LaVeist, T., Pollack, K., Thorpe, R. Jr., Fesahazion, R., \& Gaskin, D. (2011). Place, not race: Disparities dissipate in Southwest Baltimore when Blacks and whites live under similar conditions." Health Affairs, 30(10), 1880-1877.

Lewontin, R. C., Rose, S., \& Kamin, L. (1984). Not in our genes. New York, NY: Random House.

Liberman M., Mulder D., \& Sampalis, J. (2000). Advanced or basic life support for trauma: Meta- analysis and critical review of the literature. Journal of Trauma and Acute Surgery, 49(4), 584-599.

Lock, M. (1987). Symptom reporting at the end of menstruation: Biological variation and cultural difference. Journal of the British Menopause Society, 18, 132-136.

Lock, M. (1993). Encounters with aging: Mythologies of menopause in Japan and North America. Berkeley, CA: UC Press.

McDonald, E. L., Powell, C., Perryman, J. P., Thompson, N. J., \& Jacob-Arriola, K. R. (2013). Understanding the relationship between trust in health care and attitudes 
toward living donor transplant among African Americans with end-stage renal disease. Clinical Transplantation, 27(4), 619-626.

Moselle, A. (2016, October 20). Will a study save victims of violence, or gamble with their lives? NPR. Retrieved from www.npr.org

Murray, T. M. (2015). Trust in African Americans health care experiences. Nursing Forum, 50(4), 285-292.

National Institute on Minority Health and Health Disparities. (2012). Important events in NIMHD history. Retrieved from www.nih.gov

Olafsdottir, A. (2007). Fundamental causes of health disparities: Stratification, the welfare state, and health in the United States and Iceland. Journal of Health and Social Behavior, 48(3), 239-253.

National Center for Health Statistics (US) Report. (2016). Health, United States, 2015: With special feature on racial and health disparities (Report No.: 2016-1232). Hyattsville, MD.

Roberts, D. (1998). Killing the Black body. New York, NY: Random House.

Roberts, D. (2009). Race, gender, and genetic technologies: A new reproductive dystopia? Signs, 34(4), 783-804.

Roberts, D. (2012). Debating the Cause of Health Disparities. Cambridge Quarterly of Health Care Ethics, 21(3).

Said, E. (1978). Orientalism. New York, NY: Random House.

Sartre, J. P. (1943). Being and nothingness. New York, NY: Gallimard.

Sharma, M., \& Kuper, A. (2016). The elephant in the room: Talking race in medical education. Advances in Health Science Education: Theory and Practice, 22(3), 761764.

Shavers, V., Lynch, C., \& Burmeister, L. (2002). Original report: Racial differences in factors that influence the willingness to participate in medical research studies. Annals of Epidemiology, 12(4), 248-256.

Sheppard, V. B., Huei-Yu Wang, J., Hurtado-deMendoza, A., Sutton, A. L., \& LaVeist, T. A. (2019). Psychometric properties of the medical mistrust index (MMI) in Latina immigrants. Behavioral Medicine, 45(2), 128-133.

Stiell I., Nesbitt L., Pickett, W., Munkley, D., Spaite, D., Banek, J.,... the OPALS Study Group. (2008). The OPALS Major Trauma Study: Impact of advanced life-support on survival and morbidity. Canadian Medical Association Journal, 178(9), 1141-1152. 
Temple University. (n.d.). PIP Trauma Trial. Retrieved from

https://medicine.temple.edu/departments-centers/clinicaldepartments/surgery/research-programs/philadelphia-immediate-transport

The Department of Health and Human Services. (2011). HHS action plan to reduce racial and ethnic health disparities. Retrieved from http://www.minorityhealth.hhs.gov/assets/pdf/hhs/HHS_Plan_complete.pdf

Trujillo-Pagan, N. (2013). Modern colonization by medical intervention: U.S. medicine in Puerto Rico. Leiden, NL: Brill.

Vice News. (2016, October 27). How two trauma surgeons are trying to save more shooting victims. Vice News. Retrieved from www.vice.com

Washington, D. A. (2009). Critical race feminist bioethics telling stories in law school and medical school in pursuit of "cultural competency." Albany Law Review, 72, 961-998.

Washington, H. A. (2006). Medical apartheid: The dark history of medical experimentation on Black Americans from colonial times to the present. New York, NY: Doubleday.

West, C. (1991). Social breakdown: Nihilism in Black America. Dissent, 38(2).

Williams, P. J. (2017). Race, the new Black: On fashioning genetic brand. American Journal of Law and Medicine, 42(2-3), 183-191.

Wilson, A. E. (2009). "Fundamental causes" of health disparities: A comparative analysis of Canada and the United States. International Sociology, 24(1), 93-113.

Yoganandan, N., \& Pintar, F. (1997). Biomechanics of penetrating trauma. Critical Reviews in Biomedical Engineering, 25(6), 485-50. 